\title{
Analysis of Heavy Metal Pollution of Superficial Soil in Urban Area
}

\author{
Chen $\mathrm{Li}^{1, \text { a }}$, Yuxiang Xie ${ }^{1, \mathrm{~b}}$,Kaichao Zhang ${ }^{2, \mathrm{c}}$ and Xidao Luan ${ }^{3, \mathrm{~d}}$ \\ ${ }^{1}$ Science and Technology on Information Systems Engineering Laboratory, National University of \\ Defense Technology, NUDT, Changsha, P. R. China \\ ${ }^{2}$ PLA Unit 63776, Weinan, P. R. China \\ ${ }^{3}$ Department of Information and Computer Science, Changsha University, CCSU, Changsha, P. R. \\ China \\ a lichen_nudt@163.com, ${ }^{b}$ xyx89@163.com, ${ }^{c} 463885581 @ q q . c o m,{ }^{d}$ xidaoluan@sina.com
}

Keywords: heavy metal; pollution; spread; pollution source; space distribution

Abstract. According to the monitoring data of content of 8 main heavy metal elements in a certain urban area, this paper conducts a modeling study on heavy mental pollution of superficial soil in cities. According to single-factor concentration evaluation standard and comprehensive evaluation standard (Nemerow pollution index), pollution state of various areas has been worked out: industrial area > traffic area $>$ living area $>$ green area in the park $>$ mountainous area. By considering variation coefficient of distribution of various heavy metal elements and correlation among them, deduce the main pollution source of different elements: As, $\mathrm{Cr}$ and $\mathrm{Ni}$ mainly come from coal combustion; $\mathrm{Hg}$ mainly comes from discard of lighting electrical appliances; $\mathrm{Pb}$ mainly comes from emission of automobile exhaust; $\mathrm{Cu}, \mathrm{Cd}$ and $\mathrm{Zn}$ mainly come from industrial residue of factories. By combining with relevant correlation coefficient, deduction test model is given.

\section{Introduction}

With rapid development of urban economy and constant increase of city population, influence of human activities on environmental quality is becoming more and more prominent. People have paid more and more attention to the check about anomaly of urban soil geological environment, and how to launch urban environmental quality evaluation and study the evolution mode of urban geological environment under influence of human activities via the mass data obtained by the check. If classified according to functions, the urban area can be divided into living area, industrial area, mountainous area, trunk road area, green area in the park, etc., and the influence degree of human activities on different areas is different. ${ }^{[1-3]}$

Now conduct a survey about the urban soil geological environment in a certain city. The investigated urban area will be divided into a web grid area with the separation distance of about $1 \mathrm{~km}$. ${ }^{[4]}$ Take samples from the superficial soil (with the depth of $0-10 \mathrm{~cm}$ ) every 1 square kilometer, test and analyze the sample via special instrument, and obtain the concentration data of various chemical elements contained in every sample. Besides, take samples from the natural area which is far away from the crowd and industrial activities every 2 kilometers as background value of elements in the superficial soil of this urban area. ${ }^{[5]}$

The rest of paper is organized as follows. The Sec. 2 lists the basic assumptions of this research. In Sec. 3 we present our analysis model of heavy metal pollution and evaluate it in Sec. 4. Sec. 5 concludes the paper.

\section{Basic Hypothesis}

Causes of spatial structure characteristics of heavy metal element content in the soil can be summarized into 3 aspects: (1) internal spatial structure of background content of heavy metal element; (2) restriction by environment variables which influence heavy metal element distribution; (3) influence of spatial structure of heavy metal element exogenous input. Within a scope of small scale, it is considered that influence of background gradient of element content and gradient of environmental influence is 
weak, so the space variation trend is not obvious. If the spatial structure of heavy metal element content in soil changes obviously, then such spatial structure is mainly caused by influence of heavy metal exogenous input. While under the influence of parent material and soil property, the causes of (1) and (2) are thought to be influence of natural factors.

The heavy metal element content in the urban area mainly comes from the inside urban environment, and influences outside the urban area will be neglected.

Quantity of pollutant discharged from the pollution source will remain unchanged.

Movement of heavy metal in soil mainly moves in the form of solute along with the soil moisture.

Concentration of heavy metal approximates constant change in geographical position.

\section{Model building and solution}

\section{Data Statistics \& Comparison}

With the collected data, average the element concentration of different functional areas, and compare them with the urban soil background value. Refer to Table 1.

Table 1. Heavy metal content of different functional areas and background value

\begin{tabular}{lllllll}
\hline $\begin{array}{l}\text { Chemical element } \\
{[\mu \mathrm{g} / \mathrm{g}]}\end{array}$ & \multicolumn{2}{l}{ Mean of soil sample } & \multicolumn{2}{l}{$\begin{array}{l}\text { Background } \\
\text { value }\end{array}$} \\
\cline { 2 - 6 } & $\begin{array}{l}\text { Living } \\
\text { area }\end{array}$ & $\begin{array}{l}\text { Industrial } \\
\text { area }\end{array}$ & $\begin{array}{l}\text { Mountainous } \\
\text { area }\end{array}$ & $\begin{array}{l}\text { Traffic } \\
\text { area }\end{array}$ & $\begin{array}{l}\text { Green area in } \\
\text { park }\end{array}$ & \\
\hline $\mathrm{As}$ & 6.27 & 7.25 & 4.04 & 5.71 & 6.26 & 3.6 \\
$\mathrm{Cd}$ & 289.96 & 393.11 & 152.32 & 360.01 & 280.54 & 130 \\
$\mathrm{Cr}$ & 69.02 & 53.41 & 38.96 & 58.05 & 43.64 & 31 \\
$\mathrm{Cu}$ & 49.40 & 127.54 & 17.32 & 62.21 & 30.19 & 13.2 \\
$\mathrm{Hg}$ & 93.04 & 642.36 & 40.96 & 446.82 & 114.99 & 35 \\
$\mathrm{Ni}$ & 18.34 & 19.81 & 15.45 & 17.62 & 15.29 & 12.3 \\
$\mathrm{~Pb}$ & 69.11 & 93.04 & 36.56 & 63.53 & 60.71 & 31 \\
$\mathrm{Zn}$ & 237.01 & 277.93 & 73.29 & 242.85 & 154.24 & 69 \\
\hline
\end{tabular}

It can be seen from Table 1 that content of all the 8 heavy metal elements in this urban area exceeds the background value, which illustrates that the urban soil has been under some certain influence, and the soil property decreases. Some elements like $\mathrm{Cu}, \mathrm{Hg}$, etc. in some functional areas have already been 10 times more than the background value, and such elements have probably turned into pollutants.

\section{Single-Factor Pollution Index Evaluation}

Single-factor pollution index formula:

$$
P_{i}=c_{i} / S_{i}
$$

In Eq. $1, i$ is the type of heavy metal element, $P_{i}$ is single-factor pollution index, $c_{i}$ is the measured concentration of the heavy metal element $i$, and $S_{i}$ is level 1 standard value in Soil Environmental Standard Value. $P_{i} \leq 1$ means that the soil has not been polluted; $P_{i}>1$ means that the soil has been polluted, and the more the value $P_{i}$ is, the more serious the pollution degree will be. The result can be referred to Table 2.

Table 2. Single-factor pollution index of soil heavy mental element in different function areas

\begin{tabular}{llllll}
\hline \multirow{2}{*}{ Chemical element } & \multicolumn{5}{l}{ Single-factor pollution index } \\
\cline { 2 - 6 } & Living area & Industrial area & Mountainous area & Traffic area & Green area in park \\
\hline $\mathrm{As}$ & 0.418 & 0.483 & 0.269 & 0.381 & 0.417 \\
$\mathrm{Cd}$ & 1.450 & 1.966 & 0.762 & 1.800 & 1.403 \\
$\mathrm{Cr}$ & 0.767 & 0.593 & 0.433 & 0.645 & 0.485 \\
$\mathrm{Cu}$ & 1.411 & 3.644 & 0.495 & 1.777 & 0.863 \\
$\mathrm{Hg}$ & 0.465 & 3.211 & 0.205 & 2.234 & 0.575 \\
$\mathrm{Ni}$ & 0.459 & 0.495 & 0.386 & 0.441 & 0.382 \\
$\mathrm{~Pb}$ & 1.975 & 2.658 & 1.045 & 1.815 & 1.735 \\
$\mathrm{Zn}$ & 2.370 & 2.779 & 0.733 & 2.429 & 1.542 \\
\hline
\end{tabular}


It can be seen from Table 2 that pollution index of $\mathrm{As}, \mathrm{Cr}$ and $\mathrm{Ni}$ is less than 1 , and it can be considered that these 3 elements have not caused pollution in this urban area; $\mathrm{Hg}$ pollution only occurs in industrial area and traffic area, but the pollution is quite serious; $\mathrm{Cu}$ has not caused pollution in mountainous area and green area in the park, but pollution in industrial area is quite server; $\mathrm{Cd}$ and $\mathrm{Zn}$ have caused pollution almost in the whole urban area, and pollution degree of $\mathrm{Zn}$ is slightly higher than that of $\mathrm{Cd}$; the pollution degree of $\mathrm{Pb}$ is the severest, the pollution index exceeds 1 in the whole urban area, and pollution state is quite severe. Compare the heavy metal pollution degree in different functional areas, and it can be known by analyzing the results that $\mathrm{Pb}$ and $\mathrm{Zn}$ pollution is the severest in living area, and $\mathrm{Cd}, \mathrm{Cu}$ pollution exists at the same time; $\mathrm{Cd}, \mathrm{Cu}, \mathrm{Hg}, \mathrm{Pb}$ and $\mathrm{Zn}$ pollution is relatively severe in industrial area, and $\mathrm{Cu}, \mathrm{Hg}$ pollution is especially severe; pollution degree in mountainous area is the lowest, only with slight $\mathrm{Hg}$ pollution; pollution in traffic area is lighter than that in industrial area, but is also severe, and $\mathrm{Zn}$ pollution is the severest; pollution in green area in the park is less, only with $\mathrm{Cd}, \mathrm{Pb}$ and $\mathrm{Zn}$ pollution, and the degree is light.

\section{Comprehensive Pollution Index (Nemerow Pollution Index) Evaluation}

Nemerow index method is adopted, and the pollution degree of multiple pollutants can be analyzed at the same time. The specific formula is as follows:

$$
P_{N}=\left\{\left[\left(\max c_{i} / S_{i j}\right)^{2}+\left(1 / n \sum c_{i} / S_{i j}\right)^{2}\right] \times 0.5\right\}^{0.5}
$$

In Eq. 2: $P_{N}$ is comprehensive pollution index of soil heavy metal; $j$ is code of urban functional areas; $i$ is the type of heavy metal element; $c_{i}$ is the measured concentration of the heavy metal element $i$; $S_{i j}$ is the soil environment standard value for reference; $n$ is the total amount of heavy metal type. $P_{N} \leq 1$ means no pollution; means light pollution; $1 \leq P_{N} \leq 2$ means moderate pollution; $2 \leq P_{N} \leq 3$ means severe pollution. The result can be referred to Table 3 .

Table 3. Comprehensive pollution index value in different functional areas

\begin{tabular}{llllll}
\hline Pollution index & $\begin{array}{l}\text { Living } \\
\text { area }\end{array}$ & $\begin{array}{l}\text { Industrial } \\
\text { area }\end{array}$ & $\begin{array}{l}\text { Mountainous } \\
\text { area }\end{array}$ & $\begin{array}{l}\text { Traffic } \\
\text { area }\end{array}$ & $\begin{array}{l}\text { Green area } \\
\text { in park }\end{array}$ \\
\hline $\begin{array}{l}\text { Mean of single-factor } \\
\text { pollution index }\end{array}$ & 1.164 & 1.979 & 0.541 & 1.440 & 0.925 \\
$\begin{array}{l}\text { Max of single-factor } \\
\text { pollution index }\end{array}$ & 2.370 & 3.644 & 1.045 & 2.429 & 1.735 \\
$\begin{array}{l}\text { Comprehensive pollution } \\
\text { index }\end{array}$ & 1.867 & 2.932 & 0.832 & 1.996 & 1.390 \\
\hline
\end{tabular}

It can be known form Table 3 that except mountainous area, pollution has formed in all other areas. Pollution in living area and green area in the park is lighter, and pollution in industrial area and traffic area is heavy. Especially in industrial area, it has reached the degree of severe pollution.

\section{Analysis of primary source of heavy metal pollution}

Variation coefficient is a normalized measure of probability distribution dispersion degree, and is the ratio between root-mean-square deviation and average value. Refer to Table 4 for variation coefficient according to the sampling result of multiple elements in this urban area.

Table 4. Variation coefficient of multiple elements

\begin{tabular}{lllllllll}
\hline & $\mathrm{As}$ & $\mathrm{Cd}$ & $\mathrm{Cr}$ & $\mathrm{Cu}$ & $\mathrm{Hg}$ & $\mathrm{Ni}$ & $\mathrm{Pb}$ & $\mathrm{Zn}$ \\
\hline Variation coefficient & 0.512 & 0.739 & 1.322 & 1.842 & 5.871 & 0.591 & 0.714 & 1.704 \\
\hline
\end{tabular}

For there can be 1 or 2 heavy metal element(s) discharged by the pollution source, linearly dependent coefficient and simulation equation among multiple elements shall be worked out in order to testify whether different elements are correlated. Refer to Table 5. 
Table 5. Simulation equation and linearly dependent coefficient between multiple elements

\begin{tabular}{lllllllll}
\hline & $\mathrm{As}$ & $\mathrm{Cd}$ & $\mathrm{Cr}$ & $\mathrm{Cu}$ & $\mathrm{Hg}$ & $\mathrm{Ni}$ & $\mathrm{Pb}$ & $\mathrm{Zn}$ \\
\hline $\mathrm{As}$ & 1.000 & 0.258 & 0.189 & 0.161 & 0.065 & 0.315 & 0.292 & 0.249 \\
$\mathrm{Cd}$ & 0.258 & 1.000 & 0.103 & 0.417 & 0.265 & 0.104 & 0.299 & 0.196 \\
$\mathrm{Cr}$ & 0.189 & 0.103 & 1.000 & 0.532 & 0.353 & 0.716 & 0.383 & 0.424 \\
$\mathrm{Cu}$ & 0.161 & 0.417 & 0.532 & 1.000 & 0.397 & 0.496 & 0.520 & 0.387 \\
$\mathrm{Hg}$ & 0.065 & 0.265 & 0.353 & 0.397 & 1.000 & 0.332 & 0.660 & 0.431 \\
$\mathrm{Ni}$ & 0.315 & 0.104 & 0.716 & 0.496 & 0.332 & 1.000 & 0.308 & 0.438 \\
$\mathrm{~Pb}$ & 0.292 & 0.299 & 0.383 & 0.520 & 0.660 & 0.308 & 1.000 & 0.493 \\
$\mathrm{Zn}$ & 0.249 & 0.196 & 0.424 & 0.387 & 0.431 & 0.438 & 0.493 & 1.000 \\
\hline
\end{tabular}

It can be seen from Table 5 that there is not much correlation among most metals. Relatively strong correlation only exists in $\mathrm{Ni}-\mathrm{Cr}$ and $\mathrm{Pb}-\mathrm{Hg}$, and the correlation coefficient is 0.716 and 0.660 respectively. In addition, $\mathrm{Cu}-\mathrm{Cr}$ and $\mathrm{Pb}-\mathrm{Cu}$ also have some positive correlation, and the correlation coefficient is 0.532 and 0.520 respectively. Variation coefficient of As and $\mathrm{Cr}$ is small, and concentration represents relatively uniform distribution in the whole city. It is slightly higher than background value, does not reach the pollution degree, the concentration is low, and possibility of coming from industrial production waste can be eliminated, so they are thought to be caused by coal combustion in daily life. In a similar way, increase of Ni concentration is mainly owing to vehicle exhaust emission and coal combustion.

$\mathrm{Hg}$ pollution mainly gathers in industrial area and traffic area, and it has not reached pollution degree in other areas. Most daily necessities contain $\mathrm{Hg}$, such as small electric switch, battery, fluorescent lamp, various parts of the computer, some measuring devices, mercury thermometer, and so on. Since the replacement pace of household appliances is slow, and compared with electrical appliances in industrial area and traffic area, the replacement rate of household appliances is lower. Therefore, in industrial area and traffic area, due to large-scale application of electrical appliances containing $\mathrm{Hg}$, such as street lamp, factory illumination device, etc., together with high consumption degree, $\mathrm{Hg}$ pollution in industrial area and traffic area is relatively severe. Another important reason is combustion of coal in factories. It can be seen from Table 2 that $\mathrm{Hg}$ pollution is severer in green area in the park than in living area. This is also because consumption of public illumination devices in green area in the park is great, so $\mathrm{Hg}$ content is higher than that in living area. $\mathrm{Pb}$ pollution is widespread in the whole urban area, variation coefficient is low, the pollution degree is above moderate, it's high pollution, and has uniform distribution. Eliminate the reason that it is caused by the pollution source which produces $\mathrm{Pb}$. $\mathrm{Pb}$ in the vehicle exhaust is high, and widely use of vehicles will naturally cause substantial increase of $\mathrm{Pb}$ content in the soil.

The variation coefficient of $\mathrm{Cr}, \mathrm{Cu}$ and $\mathrm{Zn}$ is relatively high, and exceeds 1 , which shows that these 3 heavy metals are also pollution caused by few pollution sources. In addition, correlation coefficient among these three in industrial area is high, and the correlation coefficient between them and $\mathrm{Pb}$ is also high. Therefore, these 3 elements are closely related to factories. We guess that these 3 elements are main constituents of production waste residue in industrial area. In terms of characteristics of these 3 elements, we reckon that main manufacturers in the industrial area are manufacturing plants of storage battery. While the small amount of other centered pollutants is related to coal combustion, and we guess that there may exist thermal power plants in this city.

\section{Evaluate Model for Analysis Results of Primary Sources of Heavy Metal Pollutants}

The following model can be used to conduct rationality test for the above analysis.

1. Suppose the heavy metal pollutants discharged by pollution sources have all been absorbed by the soil.

2. Suppose heavy metal pollution in urban areas results from pollutants inside the urban areas, and influence of pollutants outside the urban area on heavy metal content in the city is neglected.

3. The pollution source discharges waste according to the standard of maximum volume restricted by the state, and the discharge volume is same in each day. 
Suppose only 1 pollution source exists in the certain area, and it produces $n$ types of heavy metal, so these $\mathrm{n}$ types of heavy metal pollution all result from that pollution source. Suppose the daily discharge volume of all heavy metal pollutants is $\left(x_{1}, \mathrm{~L}, x_{n}\right)^{T}$, the measured content of these heavy metals in the soil is $\left(w_{1}, \mathrm{~L}, w_{n}\right)^{T}$, the background value is $\left(z_{1}, \mathrm{~L}, z_{n}\right)^{T}$, and then the pollution volume of $\mathrm{n}$ types of heavy metal elements will be $\left(y_{1}, \mathrm{~L}, y_{n}\right)^{T}=\left(w_{1}, \mathrm{~L}, w_{n}\right)^{T}-\left(z_{1}, \mathrm{~L}, z_{n}\right)^{T}$.For pollution in this area is only caused by one source, it can be known from Hypothesis 3 that $\left(x_{1}: \mathrm{L}: x_{n}\right)^{T} \approx\left(y_{1}: \mathrm{L}: y_{n}\right)^{T}$. The above formula can be transformed into $\left(y_{1}: \mathrm{L}: y_{n}\right)^{T}=k\left(x_{1}: \mathrm{L}: x_{n}\right)^{T}$, and $k$ is proportional constant, which means that $y_{i}$ and $x_{i}$ can be simulated as linear relation $Y=k X$. On the contrary, the linearly dependent coefficient $r$ between daily discharge volume $X_{i}$ of any source and heavy metal pollution value $Y$ in the area can be calculated, and if there is positive correlation between daily discharge volume of this source and element pollution in this area, which means $r>0.5$. The heavy metal has caused pollution to this area.

Extend it to multi pollution sources, we can get:

$$
Y=\sum k_{i} X_{i}
$$

If the daily pollutant discharge volume $X_{i}(i=1,2, \mathrm{~L} n)$ of some related pollution sources and the pollution element content $Y$ are given, the contribution ratio of several pollution sources to the polluted areas can be determined according to Eq. 3, and the main pollution source among these can be further determined.

\section{Conclusions}

Different utilization methods of people for lands will have a great influence on heavy metal content distribution in the soil. Via single-factor pollution index and Nemerow comprehensive pollution index, the pollution degree of different heavy metal elements in different functional areas can be obtained, and the result shows that pollution in industrial area and traffic area is the severest. In functional areas like living area, industrial area and traffic area where human activities are concentrated, pollution of heavy metal is relatively severe; while in functional areas like park and scenic area where human activities are comparatively rare, pollution of heavy metal is light.

\section{Acknowledgments}

This work was financially supported by the Hunan Provincial Natural Science Foundation of Hunan (No. 14JJ3010), the National Natural Science Foundation of China (No. 61571453) and the Key Research Foundation of Education Bureau of Hunan Province, China (No. 15A020).

\section{References}

[1] Y. Liu, Tang Q, Bai Z., Zhang X., Zhang B, Study on Heavy Metal Pollution in Cultivated Land Based on Geological Accumulation and Nemerow Index, Chinese Agricultural Science Bulletin. 25 (20), pp. 174-178 (2009)

[2] C. Zhang, Denotative Meaning of Spatial Variation Characteristics of Soil Heavy Metal Content and Pollution Source Identification in the Polluted Site, Soils. 38(5), pp. 523-533 (2006)

[3] Y. Tian, X. Guo, X. Liu, Study on Soil Heavy Metal Pollution in Different Functional Areas in Beijing City, Environmental Science \& Technology. 33 (2010)

[4] X. Wu, G. Pan, Primary Investigation of Soil Heavy Metal Distribution in Different Functional Areas in the City, Acta Pedologica Sinica. 42 (2005)

[5] B. Qin, Modeling and Simulation of Heavy Metal Pollutant Movement in Soil Environment System (2009) 